Research Article

\title{
Analysis of Land Surface Temperature Evolution Based on Regional Road Scope
}

\author{
Fabao Liu $\mathbb{D}^{1},{ }^{1}$ Xingli Jia $\mathbb{D}^{\circ},{ }^{1}$ Wenbin $\mathrm{Li}^{2}{ }^{2}$ Ao Du, ${ }^{1}$ and Dang Wang ${ }^{1}$ \\ ${ }^{1}$ School of Highway, Chang'an University, Xi'an 710064, China \\ ${ }^{2}$ Shaanxi Ankang Highway Management Bureau, Ankang 725000, China \\ Correspondence should be addressed to Xingli Jia; jiaxingli@chd.edu.cn
}

Received 7 February 2020; Revised 8 June 2020; Accepted 10 June 2020; Published 12 August 2020

Academic Editor: Valeria Vignali

Copyright (c) 2020 Fabao Liu et al. This is an open access article distributed under the Creative Commons Attribution License, which permits unrestricted use, distribution, and reproduction in any medium, provided the original work is properly cited.

To balance sustainable road construction and environmental impact, intrinsic relationships between regional road networks and land surface temperature (LST) along the roads must be examined. In this study, we hypothesize that expanding road networks can affect the LST within a given region. Thus, we determined the influence of varying road grades on the surrounding LST. Using an improved single-window algorithm with reasonably adjusted water vapor parameters, LST data for the relevant areas were extracted from Landsat 8 data. Analyzing these data revealed that, in the improved single-window algorithm, the MOD05 L2 water vapor parameter could obtain results, indicating that road grades are positively correlated with LST changes when road network mileage is increased. In addition, we found that LST was increased by highways and low-grade roads over distances of $180 \mathrm{~m}$ and $150 \mathrm{~m}$ compared with the surrounding area, respectively. Furthermore, LST was affected by road interchanges over a distance of $300 \mathrm{~m}$ and by intersections formed by low-grade roads over $150 \mathrm{~m}$; both have a linear nonuniform influence on the propagation models. Finally, we determined that different highways in the LST radiation range can interact to form an LST concentration zone, resulting in further LST increases.

\section{Introduction}

Land surface temperature (LST) is a favorable indicator for the study of environmental conditions, and the use of LST indicators as a useful research object in regional energy change discussion is also increasing [1-5]. As the infrastructure construction of the strip land, the roads will have an impact on the LST of the area along the roads due to the construction of it and the subsequent occupation due to the land occupation and itself. In addition, with the continuous development of social needs, the mileage of road networks is increasing, and the LST within the road's domain will also change due to the influence of the road itself, thus affecting the surrounding environment. At present, most of the studies on regional LST are to study a large scope of urban areas [6-8], but there are fewer studies on LST changes within the road areas.

As an important indicator of environmental change, most LST researchers use it as an important characterization object for surface energy evolvement and environmental change $[1-5,9,10]$. However, in addition to the use of realtime monitoring and measurement methods [11], researchers have made it more convenient to adopt satellite data to study regional LST $[12,13]$. Therefore, a large number of researchers use satellite data for regional LST analysis, not only from the inversion algorithms to explore and make improvement but also in the selection of source data in different aspects of screening. For example, some researchers have summarized and analyzed several major LST inversion methods and compared their accuracy $[14,15]$. However, different parameter selection on the inversion algorithms will also cause differences in accuracy. For example, some researchers use the split-window algorithm from MODIS product for temperature inversion [16]. As the algorithm is relatively sensitive to the bands 31 and 32 , the bare soil parameters are adjusted in the inversion algorithm, and MODIS data are used to verify the impact of LST temperature inversion accuracy. However, some studies 
have shown that the single-window algorithm has relatively higher precision from LANDSAT TM 5 [17]. However, the single-window algorithm adopted a few parameters, which is greatly affected by water vapor parameters. But studies have shown that single-window algorithm has certain advantages in temperature inversion at high altitude areas [18]. The split-window algorithm also plays an important role in the study of LST discussion. Some studies have shown that, using MODIS products to invert the LST in the split-window algorithm, the accuracy is higher in regions with more land content $[13,16]$. It can be seen that there are differences in the adaptability of different algorithms, and there will be an impact on the accuracy of the inversion results due to the interference of the source data cloud [11]. Some researchers have addressed this problem and combined the advantages of thermal infrared (TIR) with passive microwave (PMW) measurements to propose the all-weather LST retrieval algorithm, and the LST retrieval algorithm method has improved the accuracy compared to the use of MODIS to extract LST [19]. Its applicability, however, requires further investigation. Therefore, the correct selection of the algorithm suitable for the study area in the LST inversion process plays an important role in the accuracy of the LST inversion results. At the same time, the effective selection of the source data is equally important in the discussion.

Different source data differ in resolution. Therefore, the selection of source data will also affect the results when the LST is inverted. It has been shown that the use of MODIS data for LST studies is fruitful, including change in urban energy and discussion of urban vegetation coverage indicators $[2,6,11-13,20-22]$. For example, in the process of using MODIS data to study the LST of urban areas, results show that the development of urbanization has a significant relationship with LST changes [2]. It has also been shown that the LST in the urban areas change greatly every ten years; the more intensive the urban area is, the more concentrated the LST will be [22]. It is indicated that the change of the original conditions caused by the different influencing factors in the urban development process will cause changes in the LST of the region, but studies on the LST change caused by road development and construction in the urbanization development process are still lacking. When researchers gradually use Landsat data to study LST, the research results are also significant [7, 23-25]. Some studies have shown that multispectral analysis methods can be used to analyze urban LST changes, and its accuracy compared with the general inversion method has been improved [3]. It is also proved that the Landsat data has certain advantages in accuracy [25]. In addition, in the study of urban LST, it is found that there is a strong linear relationship between urban area density and LST, while urban green space use is negatively correlated with LST [7]. However, the result only discusses the relationship between LST changes and its influencing factors. There is no research on the specific quantification of influencing factors. In addition, some studies have used regression analysis to quantify the increase and decrease between urban tree growth and decrement with temperature value in urban LST analysis [26]. It is indicated that the vegetation factors have an important influence on the LST in the evolving process. In some studies, the change of vegetation coverage has also gradually evolved into the LST evolvement [9, 10,27], and its overall impact is negative. In the study of LST, the influencing factors are diverse. Most of the current studies focus on different interference factors, and some studies focus on regional LST study from land use changes $[27,28]$. Studies have shown that the relationship between land use and urban LST is a positive correlation, and the higher the land utilization rate, the higher the LST performance [4]. In addition, some researchers have improved the research accuracy and discussed the intrinsic relationship between LST and its influencing factors. Therefore, a large amount of data is used as the research basis, and a variety of source data combination analysis is performed; for example, a plurality of source data are combined for LST analysis [29], which provides some ideas for the subsequent research due to insufficient source data. Similarly, researchers have explored the mechanism of the effect of vegetation index and built index on LST by continuously refining the raster data [30] and by using these grids to perform weight refinement analysis of different grid sizes [31] in order to study its impact on the LST.

As a product of infrastructure construction, roads have similarities and differences with the internal factors of LST caused by the development of urban areas. However, the construction of road will also have an impact on the LST due to its own construction [32]. Studies have shown that the temperature zone is formed in the road area [5], but there is no specific analysis of the scope and impact of the specific temperature zone. Because the road is a belt-like structure, its construction will also affect the area along the road $[33,34]$, and the road itself will also affect the vegetation and soil along the road $[35,36]$. At present, most studies only discussed the LST of urban regional road network [37] and emphasized on urban areas [38]. However, as an important part of the development of social foundation, attention should be paid to the sustainable development in the continuous development process of road $[39,40]$, and in-depth research and analysis should be conducted due to its own changes. In the text, in order to discuss the change of LST along the road domain caused by the continuous construction of the road and the impact on the surrounding environment, from the perspective of the LST along the road, Landsat 8 remote sensing image data is used to internally analyze the LST of the regional road network area and analyze the evolvement of the influence mechanism of the LST along the road during its continuously changing process and at the same time explore the impact factors of the road itself. It is aimed at guiding the road network encryption planning process from the LST aspect in the future and helping with the environmental protection, which is of great significance to the sustainable and healthy development of the road.

\section{Materials and Methods}

In this paper, according to the characteristics of road network structure in different regions, the paper selects Jincheng City, Shanxi Province, China, as the main road 
network LST discussion area, where there is a ring structure and the mileage of road network is increasing. Other grades of road in the study area cannot meet the requirements of highway construction scale regardless of the width or the traffic volume; thus the research objects are divided into highways and other grades of road in the paper. The geographical location of the research area is $112^{\circ} 46^{\prime} 30^{\prime \prime} \sim 112^{\circ} 56^{\prime} 30^{\prime \prime} \mathrm{E} ; 35^{\circ} 27^{\prime} 30^{\prime \prime} \sim 35^{\circ} 32^{\prime} 30^{\prime \prime} \mathrm{N}$, and the position is shown in Figure 1.

For the study of LST, many scholars used different satellite images for discussion, mainly including MODIS and Landsat 8 [41, 42]. Among them, the MODIS data have a lower spatial resolution than the Landsat 8 data; thus, the LST inversion over a large area, such as the urban area, can have satisfactory results. However, due to the small range of road compared with urban area, this paper chose Landsat 8 data with higher spatial resolution as the raw data for extracting LST in order to improve the accuracy of LST inversion and to facilitate the analysis of road network LST evolution. The research data in this paper was obtained from Landsat 8 source data (http://www.gscloud.cn/) and the MOD05 L2 water vapor data was downloaded from NASA's official website (https://ladsweb.modaps.eosdis.nasa.gov/ search/). Moreover, the climate conditions in the study area in April were relatively better, and the source data had the least interference due to cloudiness. Therefore, in the selection of data, in order to prevent the data of different months from affecting the results, and to reduce the impact of time interference of source data, the data extraction is carried out from the road network area of LST data from April 2013 to April 2018. However, due to the large amount of image cloud interference in April 2016, it was replaced by May 2016, and the other data extraction is from the same month. Similarly, some studies have chosen to replace the source data of neighboring months in the case of large interference of source data [43]. In addition, studies have used different data in case of insufficient data [29]; the results proved that they both had achieved better inversion results.

In this paper, Arcgis 10.2 and ENVI 5.0 software are applied to study the regional road networks in the LST extraction process, and the visual method and related statistical data are used to extract the road networks. Figure 2 shows the road network of Jincheng in 2013 and 2018, respectively. Then, the road network vector data for LST analysis is established. The highway road network in the paper established a buffer analysis area with a radius of $80 \mathrm{~m}$, while the other grades of road networks established a buffer analysis area with a radius of $40 \mathrm{~m}$. Thus, the inversion results of the LST with a grid size of $30 \mathrm{~m} \times 30 \mathrm{~m}$ are obtained.

Recently, there are relatively few studies on the road network of LST using the surface thermal characteristics reflected by Landsat thermal infrared sensor (TIRS). As for some mature models [14], the satellites can be divided into single-window algorithm and split-window algorithm. The difference is in the use of a thermal infrared channel in the Landsat TIRS or two thermal infrared channels to invert the LST.
According to the US Geological Survey (USGS), it is found that, due to the influence of stray light outside the TIRS field of view, the calibration parameters of the thermal infrared band are in error and need to be corrected. For TIR $1,0.29 \mathrm{~W} /\left(\mathrm{m}^{2} \cdot \mathrm{sr} \cdot \mu \mathrm{m}\right)$ is subtracted from the radiation data at the top of the atmosphere, and $0.51 \mathrm{~W} /\left(\mathrm{m}^{2} \cdot \mathrm{sr} \cdot \mu \mathrm{m}\right)$ is subtracted for TIR 2. The brightness temperature at the sensor measured by the corrected TIR 1 will decrease by $2.1 \mathrm{~K}$, and the TIR 2 will decrease by $4.4 \mathrm{~K}$. Due to the high uncertainty of TIR 2 band correlation calibration, the official recommendation has not relied on its quantitative analysis of TIRS data [44]. In February 2017, the stray light correction algorithm was developed and implemented into the processing system. The preliminary evaluation results show that the error of TIR 1 after stray light correction is reduced from $2.1 \mathrm{~K}$ to $0.3 \mathrm{~K}$, and the error of TIR 2 is reduced from $4.4 \mathrm{~K}$ to $0.19 \mathrm{~K}$. However, the use of stray light correction and splitwindow atmospheric correction technology is still under evaluation. Until then, the TIR 2 band was not recommended for the inversion of LST [45]. Xu Hanqiu used the improved single-channel (ISC) algorithm to invert LST based on TIR 1 and compared it with split-window (SW) algorithm. The study found that the two SW algorithms are proposed for the Landsat 8-band characteristics, but the error is much larger than the $\mathrm{SC}$ algorithm, reaching $5.75^{\circ} \mathrm{C}$ and $17.99^{\circ} \mathrm{C}$, respectively, and the inversion effect is not ideal [46]. The conclusions of this study are consistent with the official USGS announcement. According to the above analysis, it is known that the calibration parameters of the TIR 2 band are unstable. Therefore, the single-channel algorithm is used to invert the LST of highway network domain in the study area. The information about the wavelengths of the two Landsat TIR channels is shown in Table 1.

In the three single-channel algorithms for Landsat 8, the radiative transfer equation (RTE) method is difficult to guarantee due to the real-time and authenticity of atmospheric parameters, while the improved monowindow (IMW) algorithm [47] and improved single-channel (ISC) algorithm [48] do not depend on the atmospheric model, so the error relative radiation transfer equation method is smaller. Among them, the IMW algorithm needs two parameters to invert LST, while the ISC algorithm only needs one parameter; fewer parameters leading to possible errors are also smaller. Therefore, the LST extraction in this study selects the TIR 1-based ISC algorithm [48] to invert the LST of the highway network area. The calculation process of the ISC algorithm inversion of the LST is shown in Figure 3. The calculation model of LST $\left(T_{s}\right)$ inversion by ISC algorithm is as follows:

$$
T_{s}=\gamma\left[\frac{1}{\varepsilon}\left(\varphi_{1} L_{\lambda}+\varphi_{2}\right)+\varphi_{3}\right]+\delta .
$$

$\varepsilon$ is the surface-specific emissivity; $L_{\lambda}$ is the radiation value received by thermal infrared sensor; $\gamma$ and $\delta$ are parameters which can be expressed by $\gamma \approx T_{\text {sat }}^{2} / b_{\gamma} L_{\lambda}$ and $\delta \approx T_{\text {sat }}-T_{\text {sat }}^{2} / b_{\gamma}$, where $T_{\text {sat }}$ is brightness temperature. When the TIR 1 of Landsat 8 is selected for surface temperature inversion, $b_{\gamma}$ takes the value of 


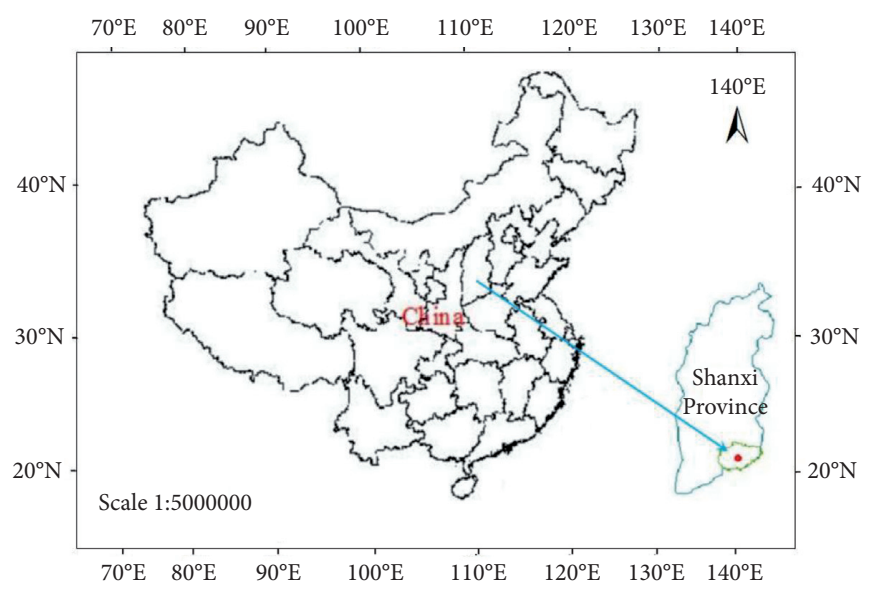

FIgure 1: Location of the study area, Jincheng City, Shanxi Province, China.

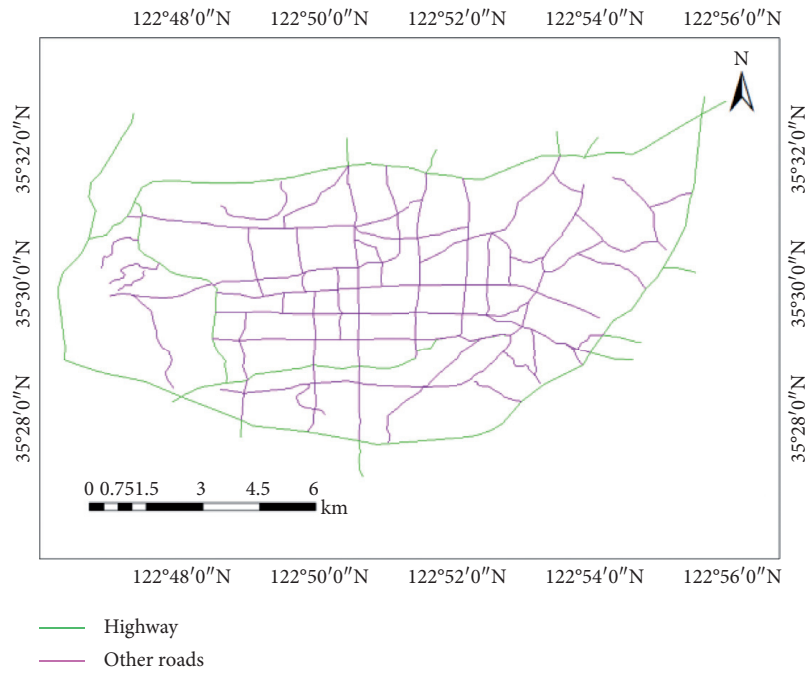

(a)

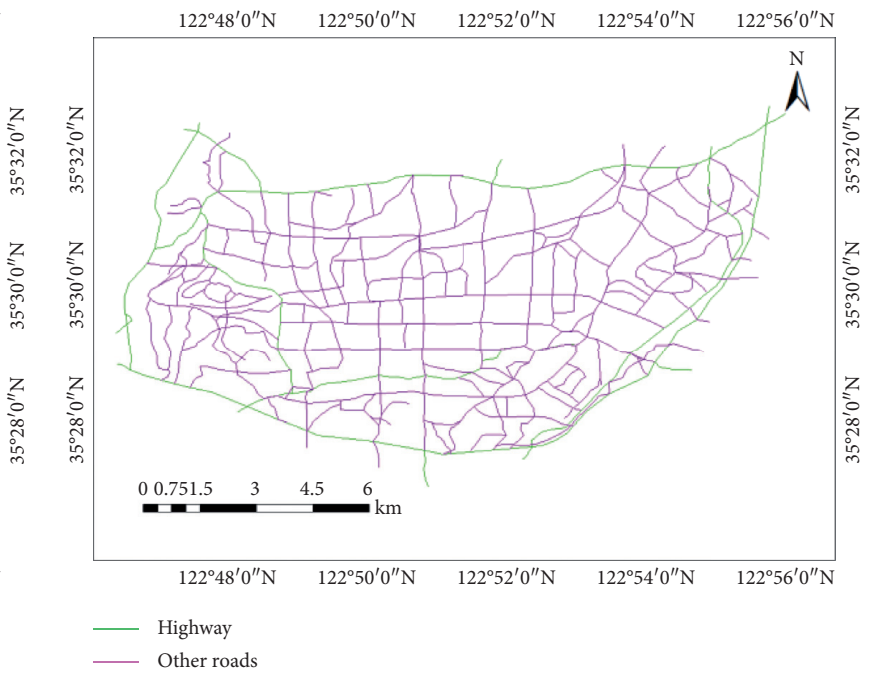

(b)

Figure 2: (a) The study of regional road networks in 2013 and (b) the study of regional road networks in 2018.

TABLE 1: Wavelengths of the two Landsat TIRS.

\begin{tabular}{lcc}
\hline Band & Wavelength $(\mu \mathrm{m})$ & Spatial resolution $(\mathrm{m})$ \\
\hline Band 10 TIRS 1 & $10.60-11.19$ & 100 \\
Band 11 TIRS 2 & $11.50-12.51$ & 100 \\
\hline
\end{tabular}

$1324 \mathrm{~K} ; \varphi_{1}, \varphi_{2}$, and $\varphi_{3}$ are the atmospheric functions; $w$ is the water vapor content coefficient.

In this paper, the research object is the road scope, so the surface coverage of the research area is regarded as a land surface composed of different proportions of vegetation and bare soil, and the surface-specific emissivity is calculated according to mixed pixels. So the surface-specific emissivity of the Landsat 8 thermal infrared band can be estimated indirectly using the multispectral band. Surface emissivity model of land surface mixed pixels in TIR 1 band is as follows:

$$
\varepsilon_{v \& s}=\varepsilon_{v} R_{v} f_{c}+\varepsilon_{s} R_{s}\left(1-f_{c}\right)+d_{\varepsilon} .
$$

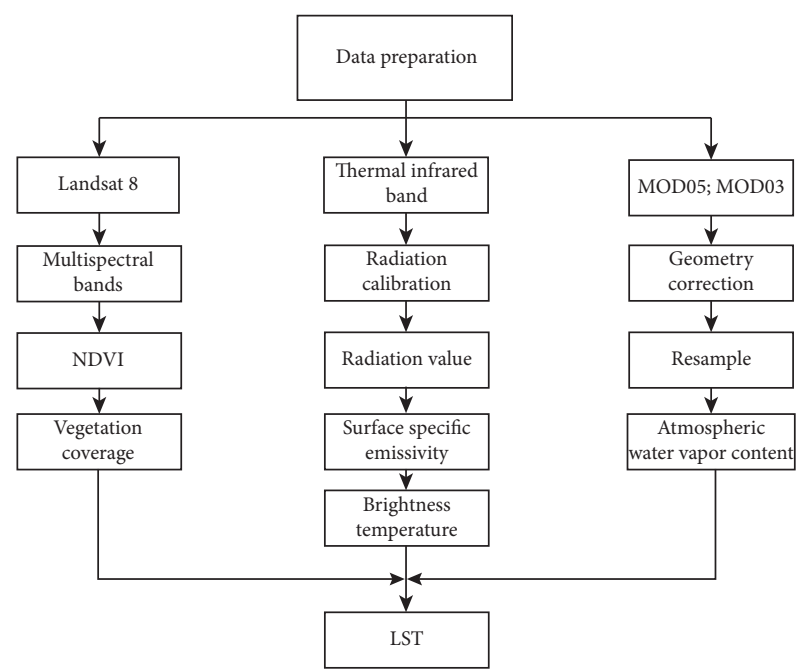

FIGURE 3: Flowchart of LST calculation. 
$\varepsilon_{v}$ and $\varepsilon_{s}$, respectively, represent the surface-specific emissivity of pure vegetation and pure bare soil in the TIR 1 band, $R_{v}$ expresses the vegetation temperature ratio, calculated by $R_{v}=0.9332+0.0585 f_{c}, R_{s}$ is the ratio of bare soil temperature, calculated by $R_{s}=0.9902+0.1068 f_{c}, d_{s}$ means the internal reflection effect value caused by the surface height difference in TIR 1 band, it is neglible in the study with the surface height difference very small, and $f_{c}$ represents vegetation coverage calculated by

$$
f_{c}=\left(\frac{\mathrm{NDVI}-\mathrm{NDVI}_{\text {soil }}}{\mathrm{NDVI}_{\mathrm{veg}}-\mathrm{NDVI}_{\text {soil }}}\right)^{2} .
$$

The atmospheric function can obtain its value in two ways. The first method is to obtain the atmospheric function by fitting the atmospheric water vapor content. The expression is

$$
\left[\begin{array}{l}
\varphi_{1} \\
\varphi_{2} \\
\varphi_{3}
\end{array}\right]=\left[\begin{array}{ccc}
0.04019 & 0.02916 & 1.01523 \\
-0.38333 & -1.50294 & 0.20324 \\
0.00918 & 1.36072 & -0.27514
\end{array}\right]\left[\begin{array}{c}
\omega^{2} \\
\omega \\
1
\end{array}\right] .
$$

When the atmospheric water vapor content exceeds $3 \mathrm{~g} /$ $\mathrm{cm}^{2}$, fitting the atmospheric function with the parameters obtained by the simulation will lead to a significant increase in the error of the calculation result. At this point, the second method of the formula derivation method can be used to calculate these parameters, as shown in

$$
\begin{aligned}
& \varphi_{1}=\frac{1}{\tau}, \\
& \varphi_{2}=-L_{d}-\frac{L_{u}}{\tau}, \\
& \varphi_{3}=L_{d} .
\end{aligned}
$$

$\tau$ is atmospheric transmittance of thermal infrared band received by thermal infrared sensor; $L_{d}$ is the downward radiation value of the atmosphere; $L_{u}$ is the upward radiation value of the atmosphere.

In this paper, when using the ISC to invert the LST of the road network area, the data source is adjusted when the water vapor value is extracted compared with the general algorithm. Compared with the direct use of water vapor source data such as MOD11 [13], the paper uses MOD03 coordinate system geometric correction combined with MOD05 L2 water vapor data to resample the water vapor data value of the study area; thus the algorithm water vapor parameters are used that have been adjusted in the paper. The aim is to improve the inversion result by adjusting the water vapor value.

\section{Results and Discussion}

The LST analysis of urban areas using the highest and lowest values is currently the commonly used LST spatial distribution analysis method [49]. In this paper, in order to better analyze the intrinsic coupling relationship between road network area and LST, the lowest temperature and the highest temperature are both discussed in the road network area to analyze the influence between the road network mileage change and the road network area LST. As for the analysis and model establishment, the Pearson test model is used as a favorable model in the correlation study [50]. There are a lot of studies on the linear fitting model and the nonlinear model in the LST research process [51-54], which are useful to discuss the inherent laws between different indicators. Table 2 shows the LST extracted from the study area. Figures 4 and 5 show the LST of the road network area in 2013 and 2018 in the study area, respectively.

\subsection{Pearson Correlation Test and Model Establishment.} According to relevant research, road construction will have a certain impact on the surrounding natural environment [39]. The total number of road network mileages in the study area changes with time, but the mileage change of the highway network in the study area is not obvious, so the influence of the mileage changes on LST is not discussed. In the study area, the mileage equivalent of other grades of road network increases significantly; therefore, other grades of road networks are mainly used to explore the regional LST for mileage factors. Then the Pearson coefficient calculated by the abovementioned other grades of road network mileage increases and its corresponding LST input SPSS is calculated, and the lowest LST and the highest LST are passed to other grades of road network area. The Pearson correlation analysis of road mileage factors has a coefficient of 0.767 and 0.772 , respectively. According to the classification of Pearson correlation coefficient, $0.8 \sim 1.0$ is extremely strongly correlated; $0.6 \sim 0.8$ is strongly correlated; $0.4 \sim 0.6$ is medium intensity correlation; $0.2 \sim 0.4$ is weak correlation; $0.0 \sim 0.2$ is very weak correlation or no correlation. Therefore, it can be known that the correlation coefficient is strongly positively correlated. It can be seen from Table 3 that the other road network mileage increases significantly in the study area, and the LST variation caused by it is also significant. The analysis shows that the impact rate of the road network area LST is fluctuating year by year. Some researchers proved that when studying the LST of urban areas, the results prove that the temperature will change greatly over time [22] but did not specifically explore the impact of road construction on LST. However, road construction will have a certain impact on the LST. When the increase of the road mileage in a certain year has a significant change from the previous years, the low LST and high LST both change significantly, and the characteristic is that the LST fluctuations are rising, but the overall impact process is characterized by a weakening trend. This shows that the other grades of road network will cause the high and low LST fluctuations of the road network area when the mileage in the study area changes relatively significantly. The final impact of the results is that the LST of other grades of road network area continues to rise to a certain extent.

Linear regression plays an important role in the process of LST research, and most studies use it $[51,52]$. In order to analyze the intrinsic relationship between the road network mileage of other grades and the LST, the paper linearly fits 
TABLE 2: LST of the study areas from 2013 to 2018.

\begin{tabular}{lccccr}
\hline Time & The whole area & Highway & Other grades of road & Interchanges & Intersections \\
\hline 2013.4 & $20.6741 \sim 34.5746$ & $23.7769 \sim 32.7215$ & $21.1361 \sim 32.8874$ & $23.7769 \sim 32.2404$ & $22.7693 \sim 31.0927$ \\
2014.4 & $18.3573 \sim 43.5246$ & $21.1623 \sim 37.1141$ & $20.5124 \sim 36.4639$ & $21.8507 \sim 35.3601$ & $21.7665 \sim 34.0013$ \\
2015.4 & $13.0031 \sim 36.3321$ & $15.0197 \sim 33.547$ & $17.1859 \sim 34.7466$ & $18.1029 \sim 32.1481$ & $18.7466 \sim 31.1404$ \\
2016.5 & $15.5093 \sim 46.6938$ & $15.5039 \sim 41.9333$ & $18.7977 \sim 41.9576$ & $19.4151 \sim 40.3719$ & $15.2166 \sim 40.5061$ \\
2017.4 & $25.1023 \sim 43.5137$ & $29.1495 \sim 41.6524$ & $27.4282 \sim 41.9069$ & $29.6129 \sim 40.8711$ & $28.1996 \sim 40.3042$ \\
2018.4 & $11.6477 \sim 33.8372$ & $11.6999 \sim 28.0726$ & $15.1224 \sim 28.369$ & $11.6999 \sim 27.1015$ & $17.4523 \sim 27.1138$ \\
\hline
\end{tabular}

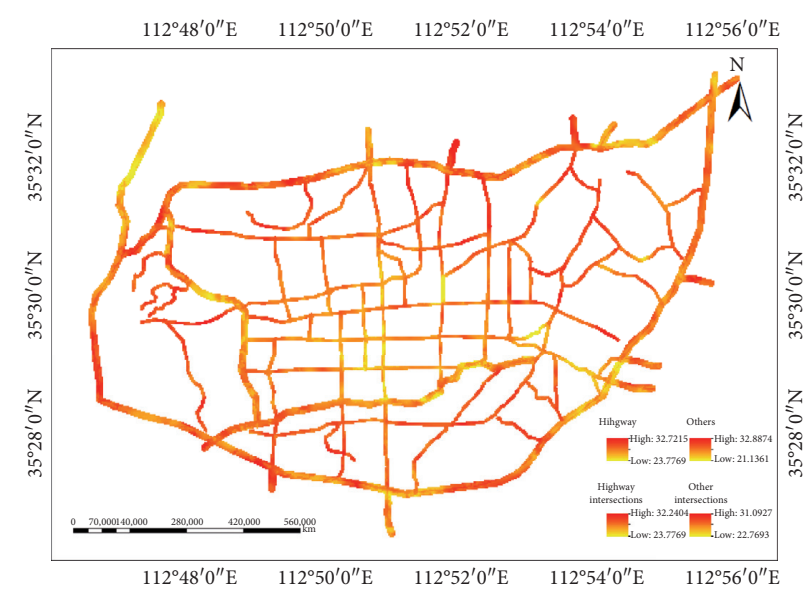

FIGURE 4: LST of Jincheng road network area in 2013.

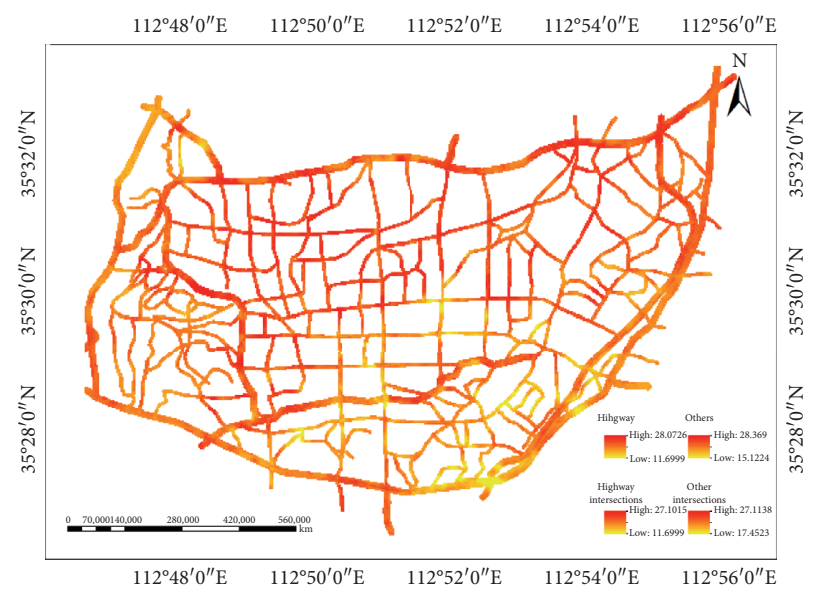

FIGURE 5: LST of Jincheng road network area in 2018.

TABLE 3: Increased mileage of high and low LST change of other grades.

\begin{tabular}{cccccc}
\hline Time & $\begin{array}{c}\text { Other road networks' } \\
\text { increased mileage }(\mathrm{m})\end{array}$ & $\begin{array}{c}\text { Mileage change rate of other } \\
\text { grades of road network }\end{array}$ & $\begin{array}{c}\text { The low LST change } \\
\text { value of other roads } \\
\left({ }^{\circ} \mathrm{C}\right)\end{array}$ & $\begin{array}{c}\text { The lowest LST change } \\
\text { rate of other roads }\end{array}$ & $\begin{array}{c}\text { Maximum LST } \\
\text { variation of other roads } \\
\left({ }^{\circ} \mathrm{C}\right)\end{array}$ \\
\hline 2014 & 1809 & +0.014223762 & +2.1551 & +0.117397439 & -7.0607 \\
2015 & 34805 & +0.269865682 & +4.1828 & +0.321677139 & -1.5855 \\
2016 & 28936 & +0.176677881 & +3.2884 & +0.212027622 & -4.7362 \\
2017 & 24649 & +0.127904779 & +2.3259 & +0.092656848 & -1.6068 \\
2018 & 22276 & +0.102484401 & +3.4747 & +0.298316406 & -5.4682 \\
\hline
\end{tabular}

the increasing percentage of mileage and the high and low LST increasing numbers. The fitting results are shown in Figure 6. The fitting effect of the low LST increase and the mileage rise percentage is better than the high LST increase, indicating that there is a linear coupling relationship between other grades of road network and its LST. Other 

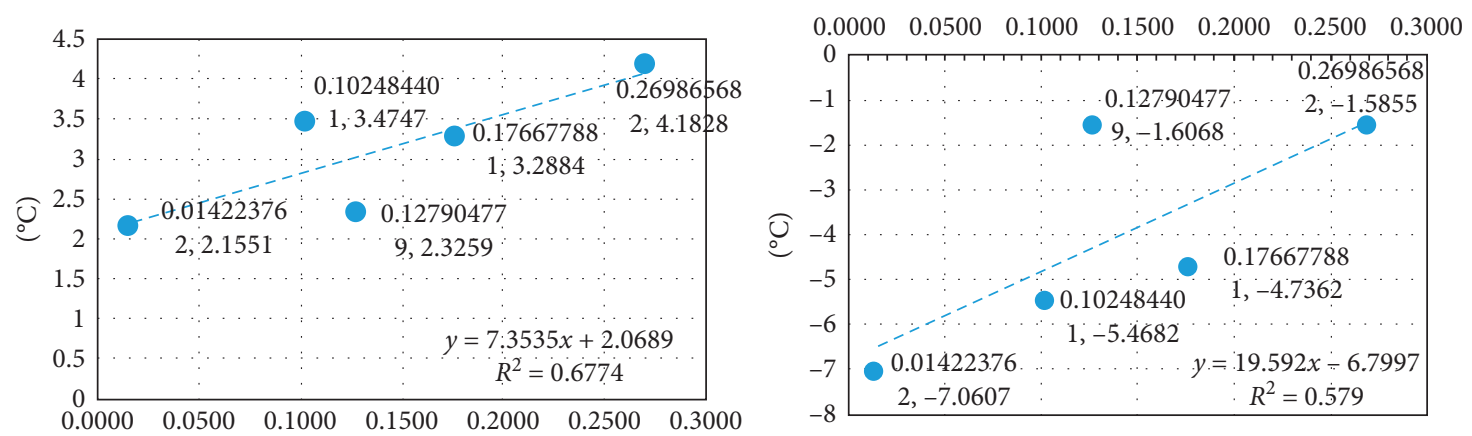

FIGURE 6: Model of mileage increase percentage with low and high LST linear regression models.

studies have shown that LST changes have a linear relationship with urban development [6]. The results also prove the effect of the increase on the road LST under the obvious rise of other grades of road mileage. On the other hand, it proves that the change in the impact on LST in the process of road construction is a gradual change, not a sudden change.

3.2. Analysis of LST Radiation on Road Network Area. There are related studies on the road LST field test to measure its temperature radiation range, but the actual measurement can only detect the single road temperature radiation within a certain range. It is hard to analyze the range of LST radiation impact on a certain road network in a certain area. However, some studies have found that a temperature zone will form within the road scope [5]. However, there is a lack of research on the LST concentrated area formed by road construction. Not only can the satellite inversion of the LST of the road network be reflected in the change of road network mileage, but also the LST in the area where the road is located can be caused just as shown in the circle marked in Figure 7. So in this paper, the impact of LST on road width is further analyzed.

In order to study the influence of LST variation caused by the width of road network area, the LST data of different widths are extracted for highways and other grades of road. As can be seen from the analysis in Figure 7, the darker the color, the higher the LST. It is obvious that there is a significant high LST point area in the highway scope, and the LST influence range is spread from the axis of the road to the sides of the road. Similarly, the results prove that LST influence law of other grades of road is consistent with highways.

To explore the spread width and propagation rate of highway and other grades of road along the road area width, the LST of different distances are extracted along the road center. In this paper, eight highway sections are extracted from the road axis by the grid size of $30 \mathrm{~m}$, and the concrete values are shown in Table 4.

It can be seen from Table 4 and Figure 8 that, as the distance from the axis of the road increases, the LST of the eight highway research sections gradually decreases. Moreover, analysing the range of $0-60 \mathrm{~m}$ separately as the highway LST concentration area, the LST gradually decreases after the $60 \mathrm{~m}$ distance range. It can be seen from Figure 8

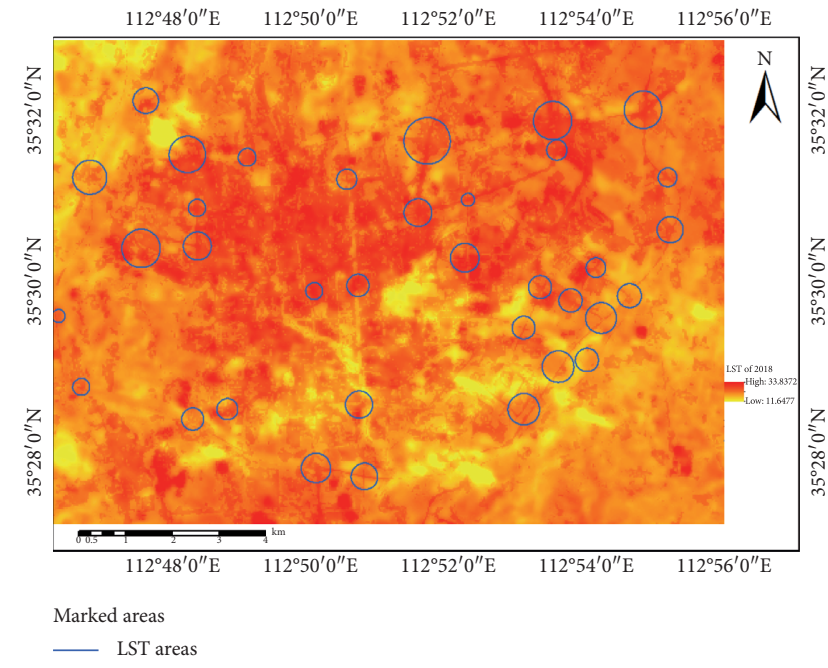

FIGURE 7: LST impact scope of road (different size circles indicate different LST affected areas). Analysis of LST radiation range on road network width.

that when the distance from the axis of the road is $180 \mathrm{~m}$, the LST has been consistent with the LST of the surrounding area. But other studies have proved that the LST propagation distance is 90 meters from the highway center [55]. Similarly, it can be seen from Table 4 that the LST value changes significantly slower when the LST is spread to $180 \mathrm{~m}$, indicating that the LST radiation range affected by the highway itself is $0 \sim 180 \mathrm{~m}$. The result proves that the LST transmission range of highway construction is more than $90 \mathrm{~m}$, and it should spread farther. And studies have shown that the higher the land utilization rate, the higher the LST [4].

On the other hand, in the discussion of extracting the LST of other grades of road network scope, the LST data of eight sections are also extracted according to the grid size of $30 \mathrm{~m}$, as shown in Table 5. It can be seen from Figure 9 that the LST of other grades of road is concentrated in the range of $0 \sim 30 \mathrm{~m}$, and the LST gradually decreases when the distance from the axis of the road keeps rising. It can be seen from Table 5 that the LST influence is very weak at $120 \mathrm{~m}$ from the road. By analyzing the average LST reduction rate, the LST reduction rate has been abrupt and slowed down at a distance of $120 \mathrm{~m}$. When the temperature data of road section 5 is extracted, the LST affected by the road itself after 
TABLE 4: LST propagation data of eight highway sections.

\begin{tabular}{|c|c|c|c|c|c|c|c|c|}
\hline $\begin{array}{l}\text { Distance from } \\
\text { axis }(\mathrm{m})\end{array}$ & Section $1\left({ }^{\circ} \mathrm{C}\right)$ & Section $2\left({ }^{\circ} \mathrm{C}\right)$ & Section $3\left({ }^{\circ} \mathrm{C}\right)$ & Section $4\left({ }^{\circ} \mathrm{C}\right)$ & Section $5\left({ }^{\circ} \mathrm{C}\right)$ & Section $6\left({ }^{\circ} \mathrm{C}\right)$ & Section $7\left({ }^{\circ} \mathrm{C}\right)$ & Section $8\left({ }^{\circ} \mathrm{C}\right)$ \\
\hline 30 & 25.342468 & 24.629242 & 24.642517 & 22.694611 & 23.073578 & 22.481682 & 21.731018 & 23.085541 \\
\hline 60 & 25.006866 & 23.341644 & 24.416229 & 22.035736 & 22.615112 & 22.228943 & 21.668518 & 22.646515 \\
\hline 90 & 22.789520 & 22.930817 & 23.057190 & 21.588287 & 20.656036 & 21.850830 & 21.355194 & 21.298096 \\
\hline 120 & 21.968567 & 22.450897 & 22.541412 & 21.448212 & 20.020203 & 21.837311 & 20.361481 & 21.447266 \\
\hline 150 & 21.538849 & 22.154205 & 22.320892 & 21.319153 & 19.476898 & 19.954620 & 20.118866 & 21.417633 \\
\hline 180 & 21.460114 & 21.987305 & 21.843719 & 20.996033 & 19.048920 & 19.800720 & 19.608185 & 21.285217 \\
\hline 210 & & & 21.487762 & & & & & \\
\hline
\end{tabular}
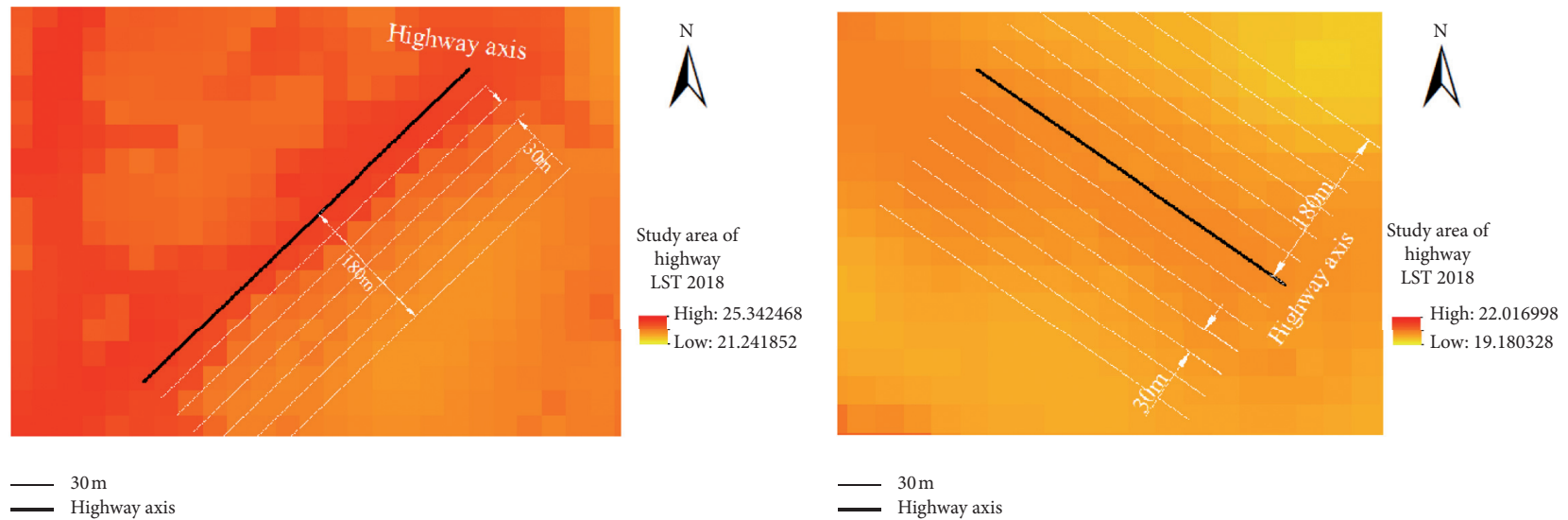

FIgURE 8: LST radiation in a typical area of highway.

TABLE 5: Other grades of road LST propagation data.

\begin{tabular}{|c|c|c|c|c|c|c|c|c|}
\hline $\begin{array}{l}\text { Distance from } \\
\text { axis (m) }\end{array}$ & Section $1\left({ }^{\circ} \mathrm{C}\right)$ & Section $2\left({ }^{\circ} \mathrm{C}\right)$ & Section $3\left({ }^{\circ} \mathrm{C}\right)$ & Section $4\left({ }^{\circ} \mathrm{C}\right)$ & Section $5\left({ }^{\circ} \mathrm{C}\right)$ & Section $6\left({ }^{\circ} \mathrm{C}\right)$ & Section $7\left({ }^{\circ} \mathrm{C}\right)$ & Section $8\left({ }^{\circ} \mathrm{C}\right)$ \\
\hline 30 & 25.074982 & 25.934235 & 22.473663 & 22.359344 & 20.374023 & 23.791107 & 24.958282 & 24.883209 \\
\hline 60 & 24.883209 & 24.611511 & 20.701263 & 20.917847 & 19.765106 & 22.478485 & 24.544556 & 23.419495 \\
\hline 90 & 23.041809 & 24.292084 & 20.237183 & 20.520874 & 18.469177 & 22.646698 & 23.945129 & 22.856171 \\
\hline 120 & 22.654694 & 23.609589 & 20.02421 & 19.826935 & & 22.11151 & 22.088287 & 22.331024 \\
\hline 150 & 22.050659 & 22.728729 & & 19.099121 & & 21.915314 & 20.777252 & 22.126038 \\
\hline 180 & & & & & & & 20.169983 & 21.938843 \\
\hline
\end{tabular}
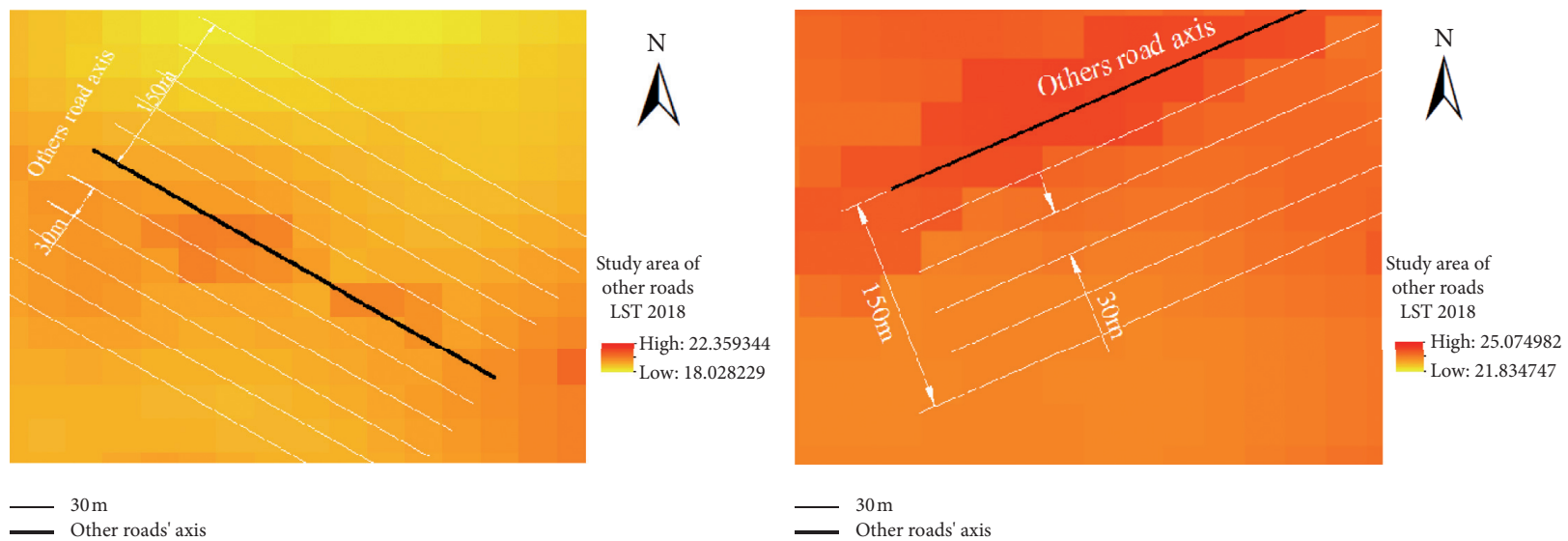

FIGURE 9: LST radiation conditions in typical areas of other grades of road.

the distance of $90 \mathrm{~m}$ is negligible. However, the comprehensive analysis from Table 5 and Figure 9 shows that the LST of other grades of road is already in the maximum impact range when it reaches $150 \mathrm{~m}$ from the axis of the road. The result of a temperature zone will form within the road scope [5], and the higher land utilization rate will cause 
higher LST [4]. The highway construction occupies a larger area compared with other grades of roads. Therefore, the spread of LST is relatively farther. Vegetation coverage and land use rate have important effects on LST [9]; road construction will destroy vegetation and occupy land, so vegetation greening should be done well during road construction.

It can be known from the above discussion that the LST will spread a certain distance. Therefore, when the distance between different roads is relatively close, the LST effects caused by the road itself will cross each other. In this paper, the cross effect of LST is also proved by the data which caused the temperature influence range in a certain road area and generated a relatively concentrated LST area. As shown in Figure 10, when the distance between two highways is relatively close, the LST propagation effects will overlap, so an LST concentration zone is formed between the two highways. It is also proved that a temperature zone will form within the road scope [5]. From Table 6, it can be seen that the LST decreases with the rise of distance between the axes of the road, but after the distance increases to $60 \mathrm{~m}$ in the discussion section, the LST value begins to rise again. Therefore, it is explained that there is a mutual influence area of LST, which leads to a relatively high LST in the entire road section region, furthermore affecting the surrounding environment of the road, which causes damage to surrounding vegetation and soil. The continuous construction of highways can mitigate the impact on the environment [40], so the distance between road sections should be considered in the construction of highways to further reduce the impact on the environment. There is a strong linear relationship between density and LST, while vegetation green space is negatively correlated with LST [7]; therefore, reducing the density of the road network will slow the rise of LST.

From Table 6, it is known that, in the LST area affected by the two highways, the LST gradually rises to the temperature value of the axis region of another highway when the distance increases to $60 \mathrm{~m}$. Comparing with the LST propagation of a single highway, it can be seen that the mode of transmission is different from that of a single highway, and it mainly shows the "V" propagation mode in the affected area of the two highways. Its propagation mode is shown as nonlinear propagation. To analyze the difference of the LST interaction on the highway, the differences in LST drop equivalents at the same distance of the highway are compared. The difference in LST drop at $90 \mathrm{~m}$ between the two road areas is $1.1911^{\circ} \mathrm{C}$, and the average drop equivalent difference of highway sections 2,3 , and 8 at $90 \mathrm{~m}$ similar to the drop equivalent difference is $1.6904^{\circ} \mathrm{C}$. By comparison, it can be seen that the temperature of the interaction zone between the two highways is relatively increased by $0.4991^{\circ} \mathrm{C}$, indicating that the LST interaction zone formed in this zone causes an LST drop value smaller than a single highway area and makes the zone keep a certain high value of LST area.

3.3. Analysis of LST Highway Interchanges' Areas. Different grades of road cross each other to form an intersection or interchange structure. While the intersection and interchanges occupy a relatively large area relative to a

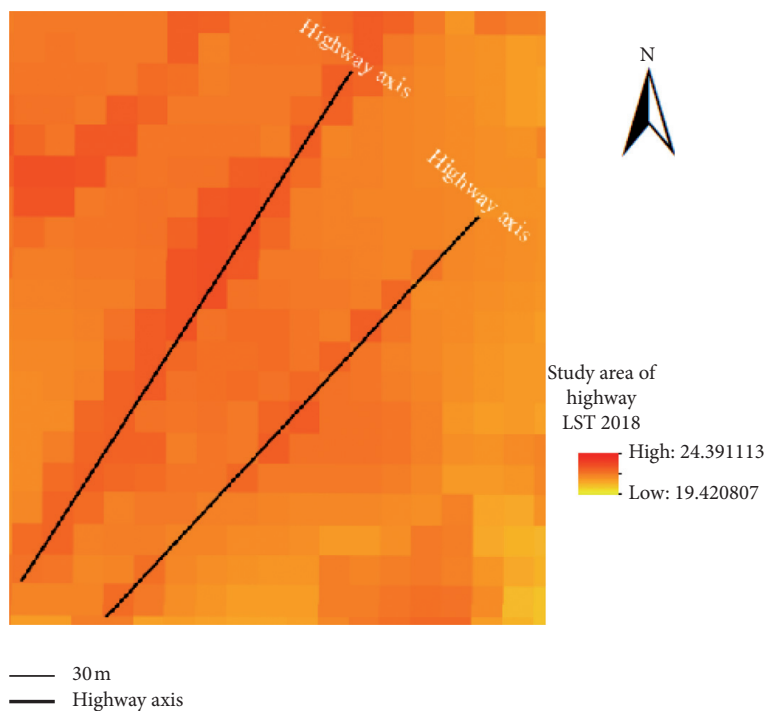

FIGURE 10: LST of highway interaction area.

TABLE 6: Road LST interacting propagation.

\begin{tabular}{lc}
\hline $\begin{array}{l}\text { Distance between the } \\
\text { axes of the two roads }(\mathrm{m})\end{array}$ & LST of interacting propagation \\
\hline 30 & 24.131042 \\
60 & $2 \mathrm{~s} 2.881012$ \\
90 & 23.169128 \\
120 & 23.436981 \\
150 & 23.834320 \\
\hline
\end{tabular}

single road, the effects of crossing between different grades of road and the same level of road are different. Using grid data to study LST is an effective method [30, 31]. For exploring the influence law of LST between different crossing points' areas, the grid data is used to analyze the LST data of different distances. In this paper, the data of the eight main interchange point areas in the study in 2018 are extracted, and the LST grid data at the interchange point areas are extracted according to the radius distance, just as shown in Table 7.

For analyzing the LST propagation law at the interchange point areas, the linear regression model is used to fit the LST value with the distance value. Using linear fitting method to study the relationship between the daily average surface temperature and its influencing factors [6], the results are negatively correlated as shown in Figure 11. It is proved that the LST diffusion in the interchanges points area linearly reduced when the distance increases, and the influence of the effect is gradually weakened. In addition, to specifically quantify the LST propagation distance at the interchanges points area, the average LST reduction rate is used. In general, a temperature zone will form within the road scope [5]. The interchange area formed by the highway has a large area and relatively little vegetation. It can be seen that the LST is relatively concentrated. The average LST reduction rate in the text is the ratio of the difference between the temperature difference and the adjacent distance. The study only analyzes the propagation 
TABLE 7: LST diffusion for eight interchanges' areas in 2018.

\begin{tabular}{|c|c|c|c|c|c|c|c|c|}
\hline $\begin{array}{l}\text { Distance } \\
(\mathrm{m})\end{array}$ & Interchange 1 & Interchange 2 & Interchange 3 & Interchange 4 & Interchange 5 & Interchange 6 & Interchange 7 & Interchange 8 \\
\hline 30 & 24.8288 & 23.4771 & 24.0960 & 25.5657 & 25.1682 & 23.6763 & 24.5691 & 23.6235 \\
\hline 90 & 24.1785 & 22.7923 & 23.8489 & 25.4618 & 24.8464 & 23.2649 & 23.8390 & 23.2223 \\
\hline 150 & 24.1301 & 20.6004 & 23.2153 & 25.2462 & 24.3517 & 22.9686 & 23.4613 & 22.7976 \\
\hline 210 & 22.7694 & 20.0827 & 22.2544 & 24.7600 & 23.8060 & 22.6639 & 22.4104 & 21.5135 \\
\hline 270 & 21.9353 & 19.2761 & 20.4554 & 24.4060 & 22.9759 & 21.9924 & 21.8843 & 21.4165 \\
\hline 300 & 19.6164 & 18.9997 & 19.7362 & 23.1598 & 22.7159 & 21.7449 & 21.7757 & 20.9201 \\
\hline 360 & & & & 22.3157 & 21.9259 & & & \\
\hline 420 & & & & & 20.8838 & & & \\
\hline
\end{tabular}

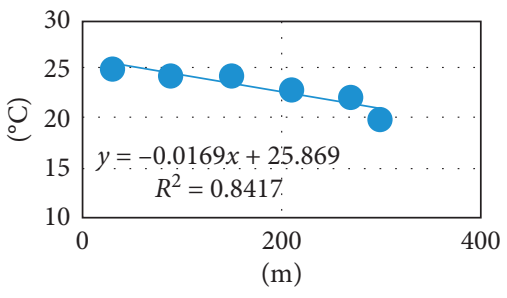

(a)

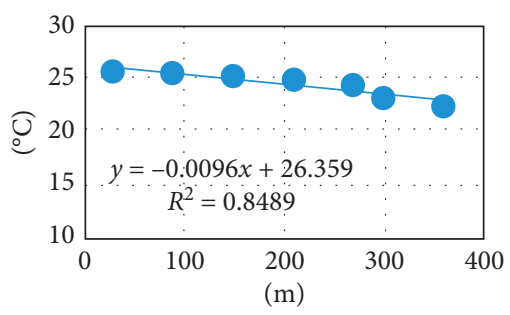

(d)

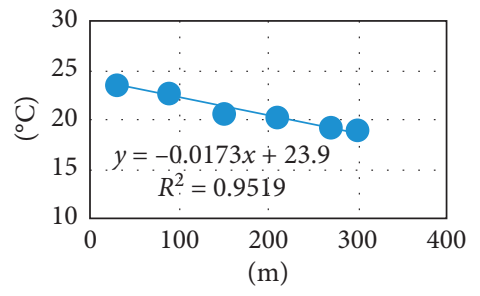

(b)

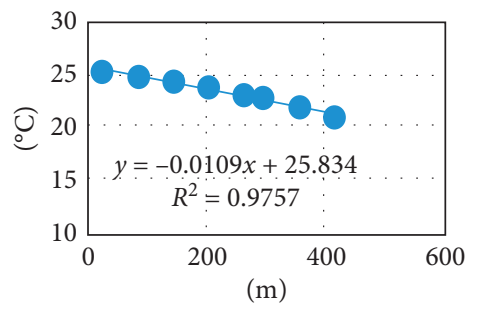

(e)

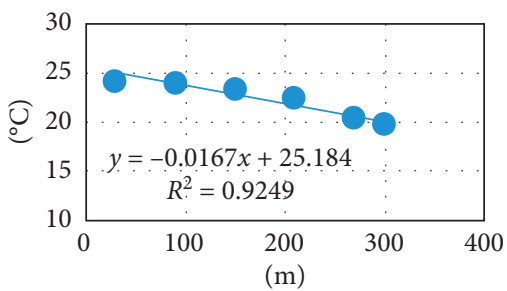

(c)

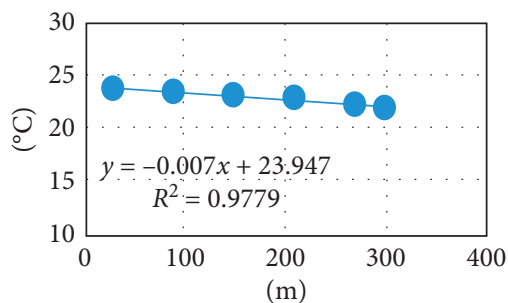

(f)

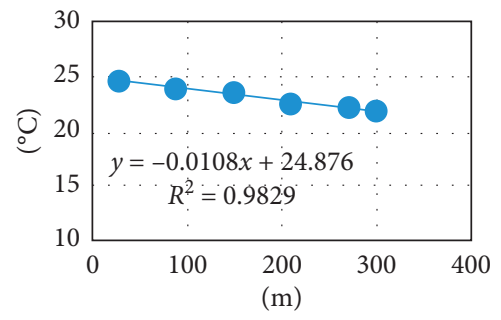

$(\mathrm{g})$

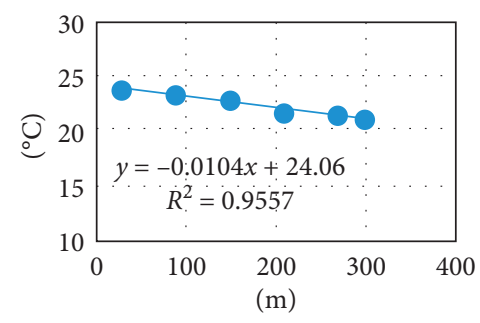

(h)

Figure 11: Temperature linear regression model of eight intersection points' area.

distance and does not consider the propagation rate [55]. In the analysis process, the LST drop propagation point is determined by comparing the average LST reduction rates to determine the LST propagation distance. When the distance is in the range of $0 \sim 210 \mathrm{~m}$, the average LST reduction rate is relatively small, indicating that the LST effect is not significantly weakened in this distance range. When the propagation distance is increased to $210 \mathrm{~m}$, the attenuation rate of interchange points 7 and 8 is suddenly increased, and then even if the distance is continuously increased, the rate is weakened as a whole. When the distance is increased to $270 \mathrm{~m}$, the average LST of elevation points of interchanges $2,3,5$, and 6 are obviously increased to the maximum value. Then, the rate of increase of the distance does not change again, until the overall trend is flat. When the distance increases to $300 \mathrm{~m}$, the average rate of interchanges 1 and 4 decreases suddenly, and then the distance increase value does not change again. It also can be proved from Figure 12 that the LST influence range of the highway interchange is consistent with the ambient temperature after $300 \mathrm{~m}$, and the range of $0 \sim 270 \mathrm{~m}$ in the highway is the main LST spread area. Beyond this distance range, the influence caused by the highway factor is weakened. Therefore, the LST analysis area of the highway interchange can be obtained from 0 to $300 \mathrm{~m}$ by the above discussion. Comparing with the highway sections, its LST spreads farther, and there are differences in the propagation mode and speed. 


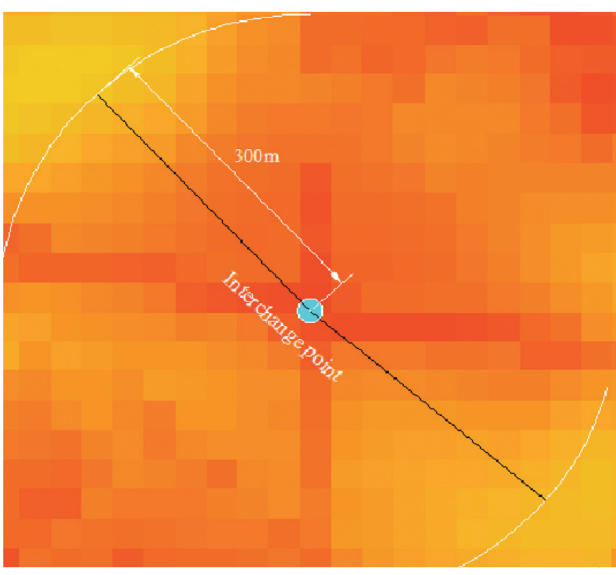

$30 \mathrm{~m}$

Interchange point

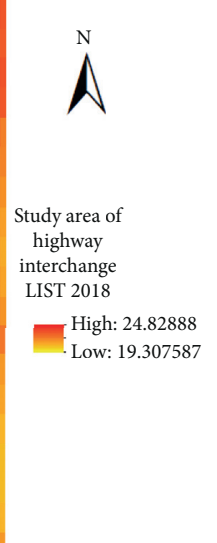

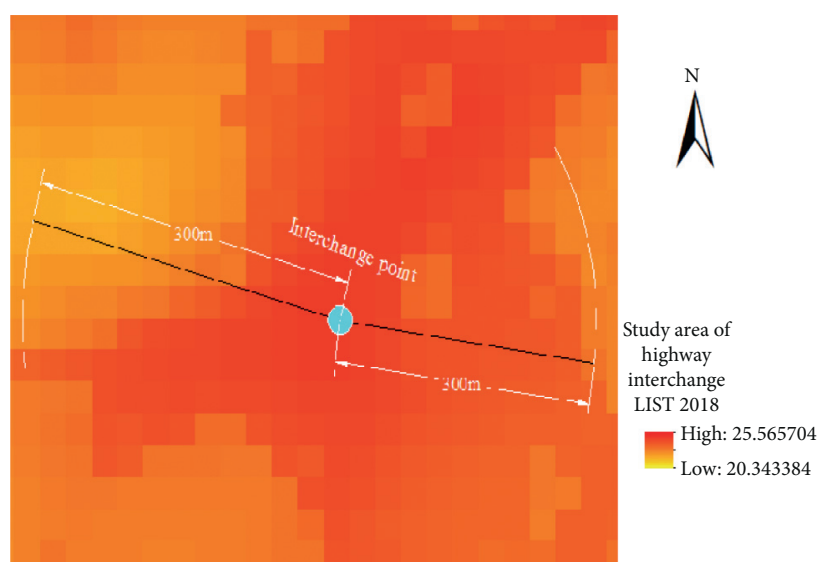

nterchange point

FIGURE 12: Temperature spread diagram of a typical interchange intersection in a highway.

TABLE 8: LST of intersection areas' diffusion in 2018.

\begin{tabular}{|c|c|c|c|c|c|c|c|c|}
\hline $\begin{array}{l}\text { Distance } \\
(\mathrm{m})\end{array}$ & Intersection 1 & Intersection 2 & Intersection 3 & Intersection 4 & Intersection 5 & Intersection 6 & Intersection 7 & Intersection 8 \\
\hline 30 & 23.3571 & 22.4715 & 21.9031 & 23.6276 & 23.3771 & 20.0807 & 25.4378 & 24.5378 \\
\hline 60 & 23.2668 & 22.4157 & 22.3730 & 23.4187 & 22.9093 & 20.1564 & 24.8414 & 24.2541 \\
\hline 90 & 22.6436 & 22.3030 & 21.5729 & 23.0832 & 22.2051 & 20.1159 & 23.8281 & 22.9567 \\
\hline 120 & 21.3749 & 21.4684 & 19.6909 & 22.3879 & 20.7164 & 19.8695 & 23.5967 & 22.5511 \\
\hline 150 & 20.6962 & 21.0381 & 19.0122 & 21.2535 & 19.9779 & 18.7861 & 23.2848 & 22.2739 \\
\hline 180 & 19.1175 & & 18.6579 & 20.9513 & 19.4736 & & 22.8868 & 22.1546 \\
\hline 210 & & & 17.9980 & & & & 22.5496 & \\
\hline
\end{tabular}

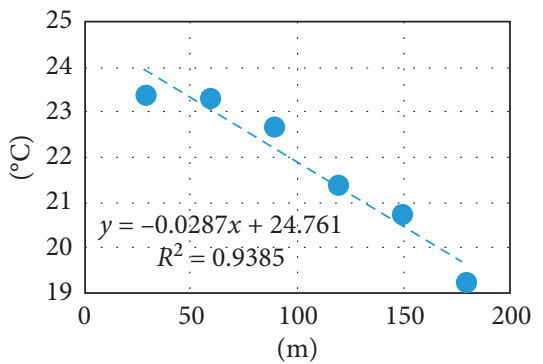

(a)

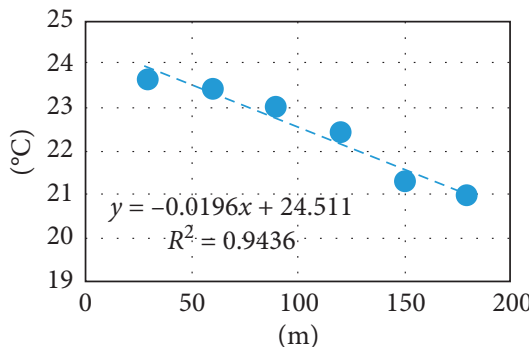

(d)

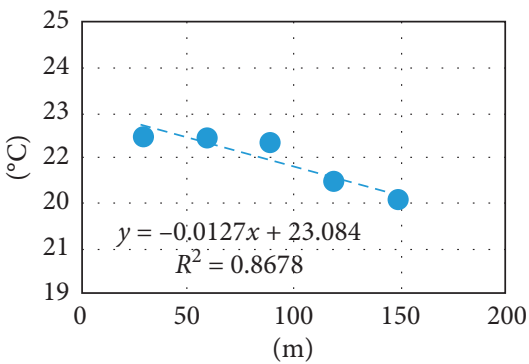

(b)

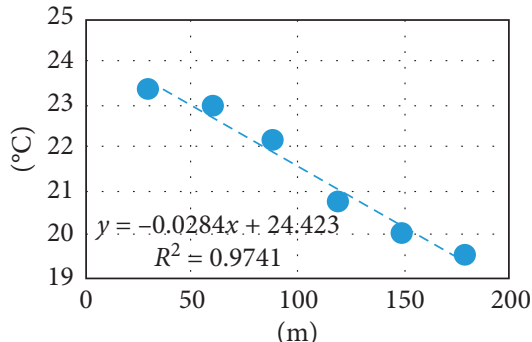

(e)

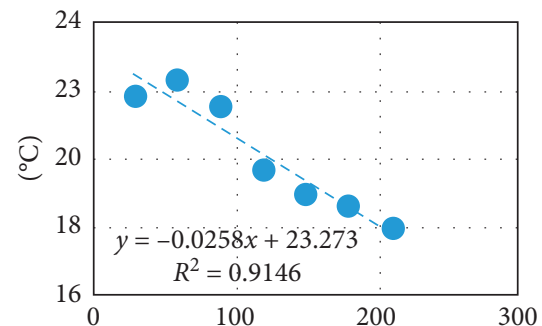

(m)

(c)

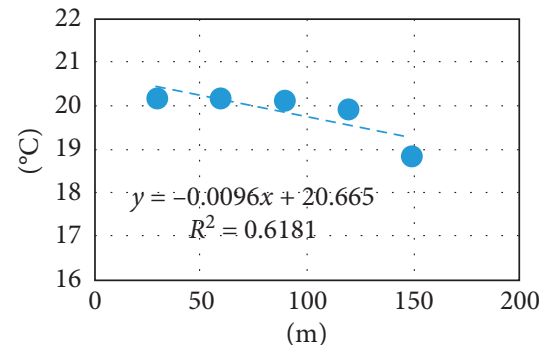

(f)

Figure 13: Continued. 


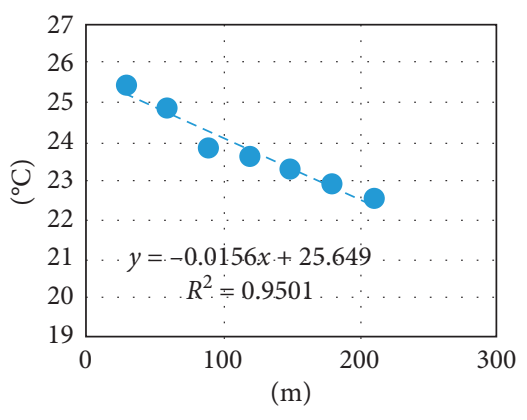

(g)

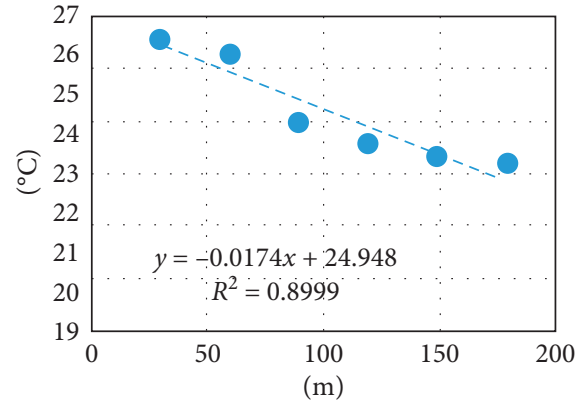

(h)

FIGURE 13: LST linear regression model of eight intersections' area.

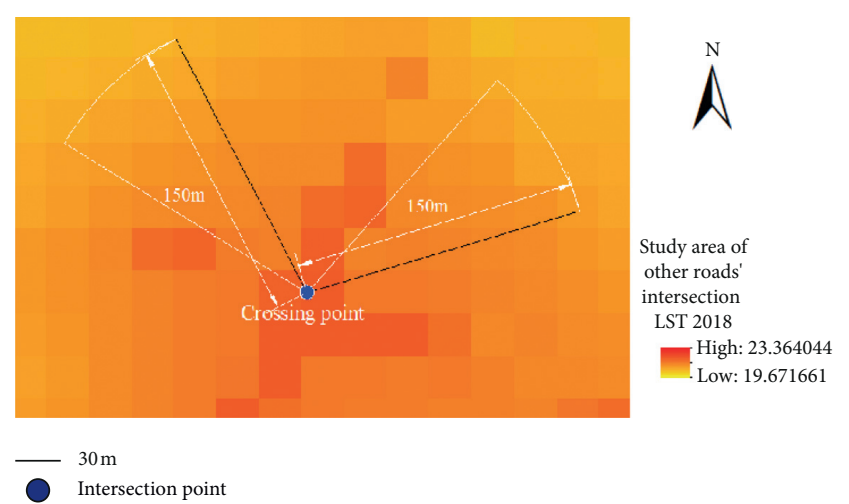

FIGURE 14: LST spread diagram of typical intersection.

3.4. Analysis of LST of Other Grades of Road Network Intersection Areas. Due to road grades, most other road networks form a level crossing structure at the intersection point. However, there are a large number of intersection points in the study area. Therefore, to explore the influence range of LST at the level of intersection areas, eight typical intersection points' areas are also selected in the paper for data extraction and analysis according to different distances. The specific LST values are shown in Table 8.

Using the LST propagation data in Table 8, the linear regression simulation between LST propagation value and distance is carried out. It can be seen from Figure 13 that the LST influence range of the eight intersection points' area is also a process of decreasing gradually with rising distance and the overall LST impact with respect to distance exhibited a strong negative correlation. From the previous research, it is known that the higher the land use, the more obvious the LST changes caused by it [4]. In addition, the spread distance in the analysis of the intersection points is also determined by calculating the LST reduction average rate to determine the LST influence boundary. By analyzing the average rate of decrease, it is known that when the distance is increased to $120 \mathrm{~m}$, the average rate of LST decrease at intersection of 1,2 , 3,5 , and 8 is abrupt. Then the rate of decrease tends to be gentle with the change of distance and no more mutation occurs. When the distance continues to increase to $150 \mathrm{~m}$, the average LST reduction rate of levels 4 and 6 is abrupt, and then the rate of decrease is relatively flat. When the distance continues to increase to $180 \mathrm{~m}$, the maximum value of the abrupt change occurs at intersection point 7 , but the average LST reduction rate of intersection point 7 has changed greatly when the distance is increased by $150 \mathrm{~m}$. It can be seen from the above discussion that the LST influence range in the intersection points area is concentrated in the range of $0 \sim 120 \mathrm{~m}$, when the distance exceeds $150 \mathrm{~m}$. It can be seen from Figure 14 that the LST change is not obvious compared with the surrounding area. Comparing with the interchange area, the LST propagation distance of the intersection is relatively closer, but the propagation method is the same.

\section{Conclusions}

The construction of highway engineering belongs to the band engineering, and its construction will have an impact on the ecology [37]. The resulting effects are generated not only in length but also in a certain width. Through the study of the paper, it can be concluded that when the construction of other grades of road continues to keep and the scale of mileage gradually increases, it will lead to a significant increase in the LST along the line of road path, and the LST changes and mileage factors along the line area increase linearly. In addition, due to the influence of road width, the LST propagation mechanism caused by the road width is also different for highways and other grades of road. Previous studies have shown that the LST range of highways is $90 \mathrm{~m}$ away from both sides of the road [55], but in this study, the Landsat 8 satellite data with better resolution is found to have an effect on the LST range of the highway within $180 \mathrm{~m}$ from the axis of the road. As for other roads, the LST influence range reaches the maximum distance of $150 \mathrm{~m}$ from the axis of the road, and the LST degree of influence gradually decreases with the rise of the distance. At the same time, it was found in the study that the highways would also have a higher LST zone due to the cross effect of LST radiation because they were within the LST range of each other. The LST propagation distances of the interchanges and the intersection in the study area are discussed, respectively. The average rate of LST reduction was calculated from the interchanges and intersection, and it is known that the value will abruptly change at the critical boundary of LST influence, after which its rate of propagation tends to be flat. Furthermore, the LST propagation mode gradually weakens 
with the trend of linear wave, so that the LST influence range of the interchanges area is mainly concentrated in the range of $0 \sim 300 \mathrm{~m}$. Meanwhile, the LST influence range of other grades of road intersection area is mainly concentrated in the range of $0 \sim 150 \mathrm{~m}$. Through the study of LST in the area along the road, it is known that the road has an influence on the LST along it. The increasing LST of the road will first accelerate the aging rate of it, thereby reducing the service life. In addition, the increase in the LST of the road will affect the vegetation of the road area, making it more difficult to survive for a long time and thus affecting the environment. Therefore, in order to ensure the healthy and sustainable development of road and the areas along them, it is of great significance to study the impact of LST on the road surrounding.

\section{Data Availability}

The research data in this paper, mainly the Landsat 8 satellite data, are downloaded through the geospatial data cloud http://www.gscloud.cn/, and the concrete data are all included in the paper.

\section{Conflicts of Interest}

The authors declare no conflicts of interest.

\section{Acknowledgments}

This research was supported by the Natural Science Basic Research Plan in Shaanxi Province of China (Program nos. 2017JQ5122 and 2018JQ4009) and the Science and Technology Project of Transportation Department of Qinghai Province (Program no. 2016-03).

\section{References}

[1] P. Sheik Mujabar, "Spatial-temporal variation of land surface temperature of Jubail Industrial City, Saudi Arabia due to seasonal effect by using Thermal Infrared Remote Sensor (TIRS) satellite data," Journal of African Earth Sciences, vol. 155, pp. 54-63, 2019.

[2] M. L. Imhoff, P. Zhang, R. E. Wolfe, and L. Bounoua, "Remote sensing of the urban heat island effect across biomes in the continental USA," Remote Sensing of Environment, vol. 114, no. 3, pp. 504-513, 2010.

[3] Z. Mitraka, N. Chrysoulakis, Y. Kamarianakis et al., "Improving the estimation of urban surface emissivity based on sub-pixel classification of high resolution satellite imagery," Remote Sensing of Environment, vol. 117, pp. 0-134, 2012.

[4] D. X. Tran, F. Pla, P. Latorre-Carmona, S. W. Myint et al., "Characterizing the relationship between land use land cover change and land surface temperature," ISPRS Journal of Photogrammetry and Remote Sensing, vol. 124, pp. 119-132, 2017.

[5] Q. Weng, H. Liu, B. Liang et al., "The Spatial variations of urban land Surface temperatures: pertinent factors, zoning effect, and Seasonal variability," IEEE Journal of Selected Topics in Applied Earth Observations and Remote Sensing, vol. 1, no. 2, pp. 154-166, 2008.

[6] M. Morabito, A. Crisci, A. Messeri, S. Orlandini et al., "The impact of built-up surfaces on land surface temperatures in
Italian urban areas," Science of The Total Environment, vol. 551-552, pp. 317-326, 2016.

[7] R. C. Estoque, Y. Murayama, and S. W. Myint, "Effects of landscape composition and pattern on land surface temperature: an urban heat island study in the megacities of Southeast Asia," Science of The Total Environment, vol. 577, 349 pages, 2017.

[8] Q. Weng, "Thermal infrared remote sensing for urban climate and environmental studies: methods, applications, and trends," ISPRS Journal of Photogrammetry and Remote Sensing, vol. 64, no. 4, pp. 335-344, 2009.

[9] M. Maimaitiyiming, A. Ghulam, T. Tiyip, F. Pla et al., "Effects of green space spatial pattern on land surface temperature: implications for sustainable urban planning and climate change adaptation," ISPRS Journal of Photogrammetry and Remote Sensing, vol. 89, pp. 59-66, 2014.

[10] A. Elmes, J. Rogan, C. Williams, S. Ratick et al., "Effects of urban tree canopy loss on land surface temperature magnitude and timing," ISPRS Journal of Photogrammetry and Remote Sensing, vol. 128, pp. 338-353, 2017.

[11] S. Muster, M. Langer, A. Abnizova, K. L. Young et al., "Spatiotemporal sensitivity of MODIS land surface temperature anomalies indicates high potential for large-scale land cover change detection in Arctic permafrost landscapes," Remote Sensing of Environment, vol. 168, pp. 1-12, 2015.

[12] W. Zhu, A. Lü, and S. Lü, "Estimation of daily maximum and minimum air temperature using MODIS land surface temperature products," Remote Sensing of Environment, vol. 130, pp. 62-73, 2013.

[13] B. H. Tang, C. Zhan, Z. L. Li et al., "Estimation of land Surface temperature from MODIS data for the atmosphere with air temperature inversion profile," IEEE Journal of Selected Topics in Applied Earth Observations and Remote Sensing, vol. 10, no. 6, pp. 2976-2983, 2017.

[14] Z.-L. Li, B.-H. Tang, H. Wu, H. Ren et al., "Satellite-derived land surface temperature: current status and perspectives," Remote Sensing of Environment, vol. 131, pp. 14-37, 2013.

[15] X. Zhenga, Z.-L. Lia b, F. Nerrya, and X. Zhang, "A new thermal infrared channel configuration for accurate land surface temperature retrieval from satellite data," Remote Sensing of Environment, vol. 231, Article ID 111216, 2019.

[16] Z. Wan, "New refinements and validation of the MODIS Land-Surface Temperature/Emissivity products," Remote Sensing of Environment, vol. 112, no. 1, pp. 59-74, 2008.

[17] J. A. Sobrino, J. C. Jiménez-Muñoz, and L. Paolini, "Land surface temperature retrieval from LANDSAT TM 5," Remote Sensing of Environment, vol. 90, no. 4, pp. 434-440, 2004.

[18] Y. Wu, N. Wang, J. He, and X. Jiang, "Estimating mountain glacier surface temperatures from Landsat-ETM + thermal infrared data: a case study of Qiyi Glacier, China," Remote Sensing of Environment, vol. 163, pp. 286-295, 2015.

[19] S.-B. Duan, Z.-L. Li, and P. Leng, "A framework for the retrieval of all-weather land surface temperature at a high spatial resolution from polar-orbiting thermal infrared and passive microwave data," Remote Sensing of Environment, vol. 195, pp. 107-117, 2017.

[20] J. Aguilar-Lome, R. Espinoza-Villar, J.-C. Espinoza, J. RojasAcuña et al., "Elevation-dependent warming of land surface temperatures in the Andes assessed using MODIS LST time series (2000-2017)," International Journal of Applied Earth Observation and Geoinformation, vol. 77, pp. 119-128, 2019.

[21] C. Wu and Z. Niu, "Modelling light use efficiency using vegetation index and land surface temperature from MODIS 
in Harvard Forest," International Journal of Remote Sensing, vol. 33, no. 7, pp. 2261-2276, 2012.

[22] P. Fu and Q. Weng, "A time series analysis of urbanization induced land use and land cover change and its impact on land surface temperature with Landsat imagery," Remote Sensing of Environment, vol. 175, no. 4, pp. 205-214, 2016.

[23] S. B. Duan, Z. L. Li, C. Wang et al., "Land-surface temperature retrieval from Landsat 8 single-channel thermal infrared data in combination with NCEP reanalysis data and ASTER GED product," International Journal of Remote Sensing, vol. 40, pp. 1763-1778, 2019.

[24] H. Li, Y. Zhou, X. Li et al., "A new method to quantify surface urban heat island intensity," Science of The Total Environment, vol. 624, pp. 262-272, 2018.

[25] V. García-Santos, J. Cuxart, D. Martínez-Villagrasa et al., "Comparison of three methods for estimating land Surface temperature from Landsat 8-TIRS Sensor data," Remote Sensing, vol. 10, no. 9, 2018.

[26] J. Rogan, M. Ziemer, D. Martin, S. Ratick et al., "The impact of tree cover loss on land surface temperature: a case study of central Massachusetts using Landsat Thematic Mapper thermal data," Applied Geography, vol. 45, pp. 49-57, 2013.

[27] H. Zhang, Z.-F. Qi, X.-Y. Ye, Y.-B. Cai et al., "Analysis of land use/land cover change, population shift, and their effects on spatiotemporal patterns of urban heat islands in metropolitan Shanghai, China," Applied Geography, vol. 44, pp. 121-133, 2013.

[28] P. Fu and Q. Weng, "Consistent land surface temperature data generation from irregularly spaced Landsat imagery," Remote Sensing of Environment, vol. 184, pp. 175-187, 2016.

[29] H. She, L. Huang, and L. Zhang, "Long-term and fine-scale satellite monitoring of the urban heat island effect by the fusion of multi-temporal and multi-sensor remote sensed data: a 26-year case study of the city of Wuhan in China," Remote Sensing of Environment, vol. 172, pp. 109-125, 2016.

[30] Z. Dai, J.-M. Guldmann, and Y. Hu, "Spatial regression models of park and land-use impacts on the urban heat island in central Beijing," Science of The Total Environment, vol. 626, pp. 1136-1147, 2018.

[31] J. Wang, Z. Qingming, H. Guo, and Z. Jin, "Characterizing the spatial dynamics of land surface temperature-impervious surface fraction relationship," International Journal of Applied Earth Observation and Geoinformation, vol. 45, pp. 55-65, 2016.

[32] Y. Lin, X. Hu, X. Zheng, X. Hou et al., "Spatial variations in the relationships between road network and landscape ecological risks in the highest forest coverage region of China," Ecological Indicators, vol. 96, pp. 392-403, 2019.

[33] L. Moretti, V. Mandrone, A. D’Andrea, and S. Caro, "Evaluation of the environmental and human health impact of road construction activities," Journal of Cleaner Production, vol. 172, pp. 1004-1013, 2018.

[34] Y. Qiao, J. Santos, A. M. K. Stoner et al., "Climate change impacts on asphalt road pavement construction and maintenance: an economic life cycle assessment of adaptation measures in the State of Virginia, United States," Journal of Industrial Ecology, vol. 24, no. 2, pp. 342-355, 2019.

[35] A. C. Hughes, "Understanding and minimizing environmental impacts of the belt and road initiative," Conservation Biology, vol. 33, no. 4, 2019.

[36] D. Azade, S. S. M. Moein, A. Ehsan et al., "The impact of road disturbance on vegetation and soil properties in a beech stand, Hyrcanian forest," European Journal of Forest Research, vol. 137, no. 6, pp. 759-770, 2018.
[37] Z. Miao, L. Pan, Q. Wang, P. Chen et al., "Research on urban ecological network under the threat of road networks-A case Study of wuhan," ISPRS International Journal of Geo-Information, vol. 8, no. 8, 342 pages, 2019.

[38] Y. Tian and J. Miao, "A numerical Study of mountain-plain breeze circulation in eastern chengdu, China," Sustainability, vol. 112821 pages, 2019.

[39] L. Wu, K. Ye, P. Gong, and J. Xing, "Perceptions of governments towards mitigating the environmental impacts of expressway construction projects: a case of China," Journal of Cleaner Production, vol. 236, Article ID 117704, 2019.

[40] Y. Rao, J. Zhang, Q. Xu et al., "Sustainability assessment of road networks: a new perspective based on service ability and landscape connectivity," Sustainable Cities and Society, vol. 40, pp. 471-483, 2018.

[41] D. Zhou, J. Xiao, and S. Bonafoni, "Satellite remote Sensing of Surface urban heat islands: progress, challenges, and perspectives," Remote Sensing, vol. 11, no. 1, 2018.

[42] X. Wu, G. Wang, R. Yao, L. Wang et al., "Investigating Surface urban heat islands in south America based on MODIS data from 2003-2016," Remote Sensing, vol. 11, no. 10, 1212 pages, 2019.

[43] X. Bai, P. Du, S. Guo et al., "Monitoring land cover change and disturbance of the mount wutai world cultural landscape heritage protected area, based on remote Sensing time-Series images from 1987 to 2018," Remote Sensing, vol. 11, no. 11, 1332 pages, 2019.

[44] Upcoming change in Landsat 8 radiometric calibration (revision). United States Geological Survey. Landsat 8 OLI and TIRS Calibration Notices [EB/OL], https://landsat.usgs.gov/ november-14-2013-change-18-radiometric-calibrationrevision..

[45] Landsat 8 TIRS Stray light correction implemented in collection 1 processing. United States Geological Survey. Landsat 8 OLI and TIRS Calibration Notices [EB/OL], https://landsat. usgs.gov/april-25-2017-tirs-stray-light-correctionimplemented-collection-1-processing.

[46] H. Xu, "Reflectivity and Surface temperature inversion of new Landsat8 Satellite images," Journal of Geophysics, vol. 58, no. 3, pp. 741-747, 2015.

[47] F. Wang, Z. Qin, C. Song, L. Tu, A. Karnieli, and S. Zhao, “An improved mono-window algorithm for land Surface temperature retrieval from Landsat 8 thermal infrared Sensor data," Remote Sensing, vol. 7, no. 4, pp. 4268-4289, 2015.

[48] J. C. Jiménez-Muñoz, J. A. Sobrino, D. Skokovic, C. Mattar, and J. Cristobal, "Land Surface temperature retrieval methods from landsat-8 thermal infrared Sensor data," IEEE Geoscience and Remote Sensing Letters, vol. 11, no. 10, pp. 1840-1843, 2014.

[49] W. Mengmeng, H. Guojin, Z. Zhaoming et al., "Comparison of Spatial interpolation and regression analysis models for an estimation of monthly near Surface air temperature in China," Remote Sensing, vol. 9, no. 12, p. 1278, 2017.

[50] R. R. Shaker, Y. Altman, C. Deng, E. Vaz, and K. Wayne Forsythe, "Investigating urban heat island through spatial analysis of New York City streetscapes," Journal of Cleaner Production, vol. 233, pp. 972-992, 2019.

[51] X. Zhu, X. Wang, D. Yan, Z. Liu, and Y. Zhou, "Analysis of remotely-sensed ecological indexes' influence on urban thermal environment dynamic using an integrated ecological index: a case study of Xi'an, China," International Journal of Remote Sensing, vol. 40, no. 9, pp. 3421-3447, 2019.

[52] J. Martins, I. Trigo, V. Bento et al., "A physically constrained calibration database for land Surface temperature using 
infrared retrieval algorithms," Remote Sensing, vol. 8, no. 10, p. 808, 2016.

[53] A. C. Adolph, M. R. Albert, and D. K. Hall, "Near-surface thermal stratification during summer at Summit, Greenland, and its relation to MODIS-derived surface temperatures," The Cryosphere Discussions, vol. 12, pp. 1-24, 2017.

[54] J. He, W. Zhao, A. Li et al., "The impact of the terrain effect on land surface temperature variation based on Landsat- 8 observations in mountainous areas," International Journal of Remote Sensing, vol. 40, no. 5-6, pp. 1808-1827, 2018.

[55] V. Nedbal and J. Brom, "Impact of highway construction on land surface energy balance and local climate derived from LANDSAT satellite data," Science of The Total Environment, vol. 633, pp. 658-667, 2018. 